\title{
Thawing Permafrost in Arctic Coastal Communities: A Framework for Studying Risks from Climate Change
}

\author{
Joan Nymand Larsen ${ }^{1,2}, *$, Peter Schweitzer $\left.{ }^{3}{ }^{(}\right)$, Khaled Abass ${ }^{4,5}{ }^{(0}$, Natalia Doloisio ${ }^{6}$, Susanna Gartler ${ }^{3} \mathbb{C}^{\circ}$, \\ Thomas Ingeman-Nielsen 7 , Jón Haukur Ingimundarson 1,2 ${ }^{\mathbb{D}}$, Leneisja Jungsberg ${ }^{8,9} \mathbb{D}^{\text {, Alexandra Meyer }}{ }^{3}$,
} Arja Rautio ${ }^{4,10}$, Johanna Scheer ${ }^{7}$, Ulla Timlin ${ }^{4}{ }^{\circ}$, Jean-Paul Vanderlinden ${ }^{6}$ and Magali Vullierme ${ }^{6,11}$

Citation: Larsen, J.N.; Schweitzer, P.; Abass, K.; Doloisio, N.; Gartler, S.; Ingeman-Nielsen, T.; Ingimundarson, J.H.; Jungsberg, L.; Meyer, A.; Rautio, A.; et al. Thawing Permafrost in Arctic Coastal Communities: A Framework for Studying Risks from Climate Change. Sustainability 2021, 13, 2651. https://doi.org/10.3390/ su13052651

Academic Editors: Marc A. Rosen and Jonas Åkerman

Received: 22 December 2020

Accepted: 25 February 2021

Published: 2 March 2021

Publisher's Note: MDPI stays neutral with regard to jurisdictional claims in published maps and institutional affiliations.

Copyright: () 2021 by the authors Licensee MDPI, Basel, Switzerland. This article is an open access article distributed under the terms and conditions of the Creative Commons Attribution (CC BY) license (https:// creativecommons.org/licenses/by/ $4.0 /)$.
1 Stefansson Arctic Institute, IS-600 Akureyri, Iceland; jhi@unak.is

2 Faculty of Social Sciences, University of Akureyri, IS-600 Akureyri, Iceland

3 Department of Social and Cultural Anthropology, University of Vienna, 1010 Wien, Austria; peter.schweitzer@univie.ac.at (P.S.); susanna.gartler@univie.ac.at (S.G.); alexandra.meyer@univie.ac.at (A.M.)

4 Arctic Health, Faculty of Medicine, University of Oulu, P.O. Box 7300, 90014 Oulu, Finland khaled.megahed@oulu.fi or khaled.m.abass@gmail.com (K.A.); arja.rautio@oulu.fi (A.R.); ulla.timlin@oulu.fi (U.T.)

5 Department of Pesticides, Menoufia University, Menoufia P.O. Box 32511, Egypt

6 CEARC Research Center, Université de Versailles Saint-Quentin-en-Yvelines/Université Paris Saclay, 78280 Guyancourt, France; brenda-natalia.doloisio@uvsq.fr (N.D.); jean-paul.vanderlinden@uvsq.fr (J.-P.V.); magali.vullierme@gmail.com (M.V.)

7 Department of Civil Engineering, Technical University of Denmark, 2800 Kgs. Lyngby, Denmark; tin@byg.dtu.dk (T.I.-N.); joasc@byg.dtu.dk (J.S.)

8 Department of Geosciences and Natural Resource Management, University of Copenhagen, 1165 Copenhagen, Denmark; leneisja.jungsberg@nordregio.org

9 Nordregio, SE-11186 Stockholm, Sweden

10 Thule Institute, University of the Arctic, P.O. Box 7300, 90014 Oulu, Finland

11 Institute for Strategic Research (IRSEM), 75007 Paris, France

* Correspondence: jnl@unak.is

\begin{abstract}
Thawing permafrost creates risks to the environment, economy and culture in Arctic coastal communities. Identification of these risks and the inclusion of the societal context and the relevant stakeholder involvement is crucial in risk management and for future sustainability, yet the dual dimensions of risk and risk perception is often ignored in conceptual risk frameworks. In this paper we present a risk framework for Arctic coastal communities. Our framework builds on the notion of the dual dimensions of risk, as both physically and socially constructed, and it places risk perception and the coproduction of risk management with local stakeholders as central components into the model. Central to our framework is the importance of multidisciplinary collaboration. A conceptual model and processual framework with a description of successive steps is developed to facilitate the identification of risks of thawing permafrost in a collaboration between local communities and scientists. Our conceptual framework motivates coproduction of risk management with locals in the identification of these risks from permafrost thaw and the development of adaptation and mitigation strategies.
\end{abstract}

Keywords: climate change; risks; permafrost; adaptation; Arctic; human exposure

\section{Introduction}

Thawing permafrost has been identified as a significant contributor to environmental, socio-economic, and cultural risks in Arctic coastal communities. Managing and reducing these risks will enable communities to reach a higher level of sustainability and increase resilience.

A risk is a threat, actual or potential to something humans value. Such risks are defined in a variety of ways by different stakeholders, including within the scientific community. For example, various formulae exist in the literature such as (1) Probabilities $\times$ Consequences [1-5] or as (2) Hazard $\times$ Exposure $\times$ Vulnerability [6-9] or as (3) the 
two-dimensional combination of events/consequences and associated uncertainties $[10,11]$ (meaning: if the events occur, what will be the consequences?).

The inclusion of the societal context and stakeholder involvement is increasingly viewed as crucial in risk management $[12,13]$ and for future sustainability, yet risk perception is often left out in prominent risk models such as the IPCC framework [14] and the risk definitions mentioned above. The recognition of the dual dimensions of risk as both physical (and scientifically measurable) and socially constructed has important consequences for both risk appraisal, which denotes the "knowledge elements necessary for risk characterization and evaluation, as well as risk management" $[15,16]$, and the development of effective adaptation and mitigation strategies. A risk framework which acknowledges that "risk" is about both science and societal values [17] balances and integrates scientific assessments of and evidence on risk factors with risk perceptions of the affected communities and creates spaces for the coproduction of knowledge and actions [12,13]. In other words, it moves beyond simply communicating risks as "matters of fact" to the affected communities to developing dialogues around "matters of concern" $[18,19]$.

In recent years, many models have been proposed to contribute to a better understanding and management of coastal regions due to the hazards and risks from climate change. Coastal zones are particularly vulnerable as they generally represent concentrated populations and a diversity of activities generating a variety of issues. Hazards and socio-technical risks are intertwined. Two central hazards are generally associated with climate change and coastal areas: coastal flooding and erosion. These threaten settlement infrastructure, such as housing, ports, roads, energy generation and distribution infrastructure, strategic facilities, and more generally reduce the potential uses of coastal areas [20,21]. Arctic coasts, broadly interpreted as an activity zone close to the coasts (extending to both the terrestrial side and including the marine near-shore environment), experience additional hazards associated with permafrost degradation. These hazards overlap and link with previously mentioned coastal hazards and impacts.

In this paper, we first briefly discuss different risk models-models that define risk and suggest processes for identifying major risks-then proceed to sketch a conceptual multidisciplinary risk framework for analyzing risks from global change in Arctic coastal communities. In our conceptual framework, we employ a broader definition of risk that allows for inclusion of cultural elements.

The development of a risk framework is a critical step within the research project Nunataryuk-a multidisciplinary EU H2020 project that aims to develop targeted adaptation and mitigation strategies for the Arctic coasts to address impacts of thawing permafrost. An overall goal of the research is to identify key risks of permafrost thaw at the Arctic coast, and to produce a risk framework that engages local communities in coproduction of knowledge, which then informs the process for the identification of coproduced adaptation and mitigation strategies to reduce the impacts of the related hazards.

Our paper is an exploratory exercise for the development of a risk management framework. The discussion and conceptual risk framework development presented here is inspired and informed in part by our fieldwork conducted in case study areas along the Arctic coasts (see MAP, Figure 1) — the coastal areas of Ilulissat, West Greenland; Longyearbyen, Svalbard; Inuvialuit Region, Beaufort Sea, Canada; Yakutia, East Siberia, Russia-and, in particular, by an international workshop held by our multidisciplinary project group to develop this framework. 


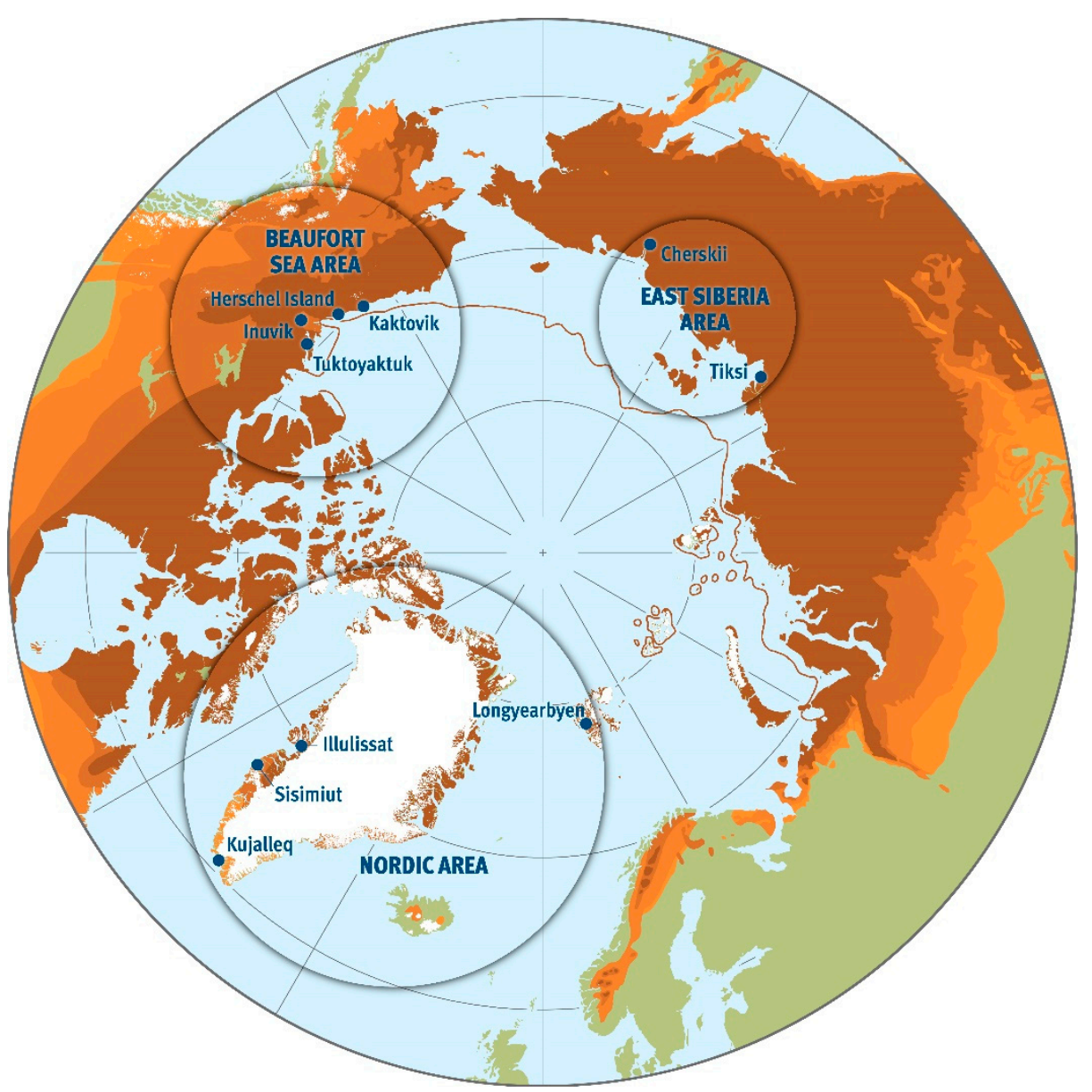

Figure 1. Map of Nunataryuk field sites. Lantuit, et al.; GRID-Arendal.

Hence, our proposed risk framework is the result of a collaborative and multidisciplinary process. The framework presented is applicable to the full spectrum of disciplines covered in the Nunataryuk project. "Nunataryuk" is based on the combination of two words: the Inuvialuktun - the Inuit language of the Inuvialiut of northwest Canadawords, "nuna" which means "land", and "taryuk", which means "coast" (the spelling of the latter word differs from dialect to dialect). While the combination of these two words does not exist in Inuvialuktun, its creation is based on conversations the project leadership had with Inuvialuit knowledge holders in developing the project. "Nunataryuk", which thus could be translated as "from land to sea", indicates the relevance of indigenous knowledge for the overall project but should not be misunderstood as privileging Inuvialuit knowledge over other forms of (indigenous) knowledge.

Scientists from various fields, roughly categorized as social sciences (anthropology, economics, human geography, and sociology), health sciences, and engineering, gathered to present and discuss different approaches to risk assessment in a workshop. The aim was to identify ways to integrate different approaches to risk assessment and risk models in order to arrive at a risk assessment framework that can be employed in the context of a multidisciplinary project on permafrost thaw, but also in other large research projects combining multiple disciplines. Our research and conceptual work are motivated by the larger Nunataryuk project aim to create partnerships with local and global stakeholders by developing physical, social, and natural indicators to be used in formulating and implementing adaptation and mitigation strategies to reduce risks from permafrost thaw. Our paper seeks to address a gap in knowledge on climate change risks along the Arctic coasts by developing a framework for identifying and managing risks and addressing the need for a risk-based framework that takes into account risk perceptions. 


\section{State of the Art: Impact of Permafrost Degradation in Arctic Communities}

Vanderlinden et al. [22] analyzed the impacts of permafrost thaw in two Arctic coastal communities (Bykovskiy, Sakha Republic, Russian Federation and Tuktoyaktuk, Northwest Territories, Canada). They identify the following local impacts of accelerated permafrost thaw: shifting of foundations, coastline erosion, changes in landscape, ecosystem changes, and changes related to food resources, destabilized transport infrastructure, and contaminant release. These impacts in turn lead to consequences in terms of building abandonment and relocation, concerns for harbor maintenance, loss of sense of place, feeling of decreasing reliability of traditional knowledge, changing ice conditions posing risks to hunters, loss of access to traditional resources, shortened ice-road season, as well as increased costs, the need for increased capital investment, impaired safety of water and country food, and related health risks. These case studies showed that while the mechanisms of permafrost thaw threat are similar in both communities, their history and institutional contexts differ. This leads to a potentially important difference in their ability to cope with permafrost thaw, which may be a central characteristic of community level permafrost thaw impact analysis. A similar physical process is socially mediated in different ways, which profoundly influence the severity of impacts.

\subsection{An Example from Engineering: Risks to Infrastructure}

Operational and well-maintained infrastructures contribute to sustaining the quality of life, as well as the cultural and economic development of society. This is especially true for Arctic communities which strongly rely on the serviceability and longevity of their facilities but need to cope with a challenging environment for construction. Notably affected by increasing stability issues and hazard occurrences due to the concomitant effects of climate change and inadequate building practices, stakeholders feel a pressing need for developing and implementing mitigation strategies [23].

On the infrastructure level or at larger scale, informed decisions must therefore be taken from planning to decommissioning [24] in order to make sure projects are complying with potential regulatory frameworks and are feasible and acceptable in terms of risks. From the planning and engineering perspectives, infrastructure monetary value and the optimization of investments [24] also represent a significant concern when financial means are limited, as in the case of many Arctic settlements. Risk assessment frameworks in engineering thereby provide a valuable tool to ensure design reliability, promote sustainability, and reach optimal decision-making and resource allocation.

The general workflow for engineering risk assessments is well-detailed in the guidelines produced by Public Safety Canada [25]. The approach mainly consists of: (1) defining the system that is being assessed; (2) identifying and characterizing individually all risks and risk event scenarios; (3) determining the level of risk by assessing quantitatively or qualitatively hazard likelihood (probability of occurrence/failure) and magnitude of consequences (severity of direct and indirect consequences); (4) ranking risks and choosing among decision-making alternatives, based on cost-benefit analysis of mitigation solutions, and treating risks that are not acceptable by implementing adaptation solutions as prevention, reduction or recovery measures [24].

Risk evaluation in engineering is built on the probabilistic nature of risk, expressed as the combination of measurable probabilities of failure and consequences. It calls for understanding and modelling of involved physical processes, and characterization of uncertainties associated with engineering models and event scenarios.

As an example, Brooks et al. [26] developed a quantitative methodology taking into account in situ and climate conditions and using reliability analysis calculations to assess risks to linear infrastructure embankments from permafrost thaw. However, data availability is often restricted in permafrost environments and quantitative risk analysis are thereby not easily feasible. As a result, engineers frequently resort to semiqualitative or qualitative methods. The protocol developed by the Public Infrastructure Engineering Vulnerability Committee [27], which consists of assessing infrastructure vulnerability with elements of 
climate change, is a good example of a successful engineering risk assessment that was applied in the Northwestern Territories, Canada [28]. This procedure principally rested upon expert knowledge to estimate probabilities and consequences using standardized rating scales.

A step towards collaborative science and stakeholder engagement was taken by Allard et al. who implemented a community-scale hazard-mapping framework in several Canadian Arctic settlements [29,30]. This multidisciplinary approach determines hazard levels by computing indices from critical driving factors, such as permafrost thermal regime, ice content, and slope angles in order to deliver hazard zonation products and support local decision-making and planning strategies. Taking into consideration stakeholders inputs and needs, recommendations for adapted building practices were provided along with maps of terrain constructability.

\subsection{An Example from Life Science: Risks to Human Health and Wellbeing}

Risk to human health is widely studied using a variety of approaches. Studies on the precise impact of environmental pollutants on human health in the Arctic are difficult to undertake and interpret because many factors influence health at the same time and to varying degrees. These include both genetic and environmental factors [31,32].

Environmental factors and the impact of warming climate and permafrost thaw will affect the volatilization and distribution of persistent organic pollutants (POPs) and heavy metals [32,33] and also increase risk of zoonotic diseases in the Arctic regions [34,35]. Many permanent organic contaminants (e.g., PCBs) and heavy metals (e.g., mercury) have declining trends in human biological matrices and biota, but the recent results of modelling and measurements showed an increase in environmental concentrations in a warmer climate [31,32]. Climate change is altering disease-vector populations, ranges, and life cycles, and together with simultaneous increased human activities, such as tourism and shipping, there are additional risks for spreading of new species (e.g., insect vectors), pathogens, and pollution among Arctic wildlife and humans [34]. One important human health risk is the possibility of remobilization of pathogens (e.g., Anthrax) and toxins from thawing permafrost from waste sites and cattle carcass burial sites due to global climate change.

\subsection{Toxicokinetic Modelling and Future Risk Prediction}

There are several research-based methodologies on how environmental contaminants affect biological processes in humans and the implications for human health risk assessments. A risk assessment of environmental pollutants is an essential tool in protecting public health. This process requires data from different sources and methodologies. For example, these sources come from in vivo toxicology, in vitro toxicology, mathematical modeling and quantitative methods, risk characterization of chemicals in food and diet, epidemiology, and the use of toxicogenomics. These may all form part of the multifaceted framework of evidence-based toxicology leading to a well-documented overall risk assessment process $[36,37]$. The main challenge in traditional risk assessment is how to link external and internal doses (contaminant levels in blood and other tissues) $[38,39]$. To circumvent this problem, quantitative risk estimation is based on reverse dosimetry of average daily dose and life-long average daily dose by toxicokinetic modelling of the contaminant blood concentration trends. The data could be from external contamination sources or from concentrations measured in blood, and the normative methods to quantify the associated risk could be via relative comparisons or quantitative risk estimates. Relative comparison of blood concentrations is a way of comparing data from different biomonitoring studies on a scale for risk assessment. However, in many cases the scale is nonlinear when estimating human health risk. Quantitative risk estimates by toxicokinetic modelling are a way of estimating hazard quotient $(\mathrm{HQ})$ for noncancer effects and the excess lifetime cancer risk (CR) based on contaminant levels in human biological matrices. A modified approach based on the traditional risk assessment process has been introduced for quantitative risk 
estimates [31]. This comprises three stages: extrapolation of exposure by pharmacokinetic modelling; incorporation of the reference dose and cancer slope factor; estimation of $\mathrm{HQ}$ and life-time cancer risk. The only deviation from the traditional exposure assessment procedure is that the average daily and average life-time doses are calculated based on the extrapolation of contaminant concentrations in blood by toxicokinetic modelling. In this model, the total dose is a sum of all exposure pathways: inhalation, ingestion, or dermal absorption, and these are all reflected in the total blood concentration of a chemical. Metabolism, excretion, and accumulation in tissues other than blood complicate the issue - that is, accumulation of organochlorines in fatty tissue, accumulation of cadmium $(\mathrm{Cd})$ in liver and kidney, and accumulation of lead $(\mathrm{Pb})$ in bone. Thus, it is important to know the toxicokinetics of the individual contaminants to get an accurate estimate. Indeed, unique genetic backgrounds, among other factors, may have a significant role in individual/population susceptibility to contaminant body burdens. Indigenous Arctic populations were identified as a population in need of improved contaminant exposure estimation tools [40].

Epidemiological studies usually include several exposure variables and health related outcomes. Several epidemiological studies were established in the circumpolar area to examine the relationship between exposure to contaminants and health outcomes [31]. Epidemiological studies usually overcome the limitation of traditional risk assessment approaches, including the single contaminant-based assessment in the common multicontaminants context, the interaction between chemical and nonchemical stressors as well as the reliance on uncertainty factors and assumptions [41].

\section{Overview of Approaches to Identification of Risks}

The examples provided above reflect that across the physical sciences, life sciences, engineering and social sciences, there are different understandings of what is a risk. This results in different approaches to risk assessment and management [42]. The natural and engineering sciences mostly define hazards as events that have negative effects on humans and their environments, and the associated risk as the probability of such a hazard occurring, multiplied by a quantification of the consequences observed or expected [42]. The scientific method is employed in order to estimate probabilities and consequences (physical harm) associated with a hazard. Social science approaches, on the other hand, criticize the definition of risk as an objective characterization of probabilities and consequences, emphasizing that risk is framed by social processes and inherently subjective and value-laden $[18,43]$. A very influential approach in this tradition, the cultural theory of risk, argues that culture and worldviews determine the way people perceive and react to risk [44]: “The way in which people perceive climate change risk is informed by their social interactions and cultural worldviews comprising fundamental beliefs about society and nature" [45]. This implies that risk is not merely a physical phenomenon that can be objectively measured, but also socially and culturally constructed: "risk does not exist "out there", independent of our minds and cultures, waiting to be measured. Human beings have invented the concept of risk to help them understand and cope with the dangers and uncertainties of life" [46]. In order for a physical phenomenon such as permafrost thaw to constitute a risk it must hence be of concern to humans in a given society.

Following this approach, risk perception emerges as a crucial dimension of risk. Risk perception could be defined as an assessment, by individuals and groups, of a hazard, its associated uncertainties, its consequences and the uncertainties associated with these consequences as expressed by society and taking into account local values and material constraints [47]. It includes "people's beliefs, attitudes, judgements and feelings, as well as the wider cultural and social dispositions they adopt towards threats to things that we value" [18]. Out of the body of literature that identifies factors that influence risk perception [48] one finding is of particular relevance for our argument, namely that risk factors (factors associated with the scientific characteristic of the risk) do not have a big impact on risk perception [49]. The communication of science-based knowledge about the 
nature of a hazard has little influence on how people perceive environmental risks and choose to deal with them [32,50], which is influenced by social, cultural and psychological factors. Consequently, risk communication and governance must pay attention to local and regional worldviews of the affected communities, socio-cultural settings, and individual and collective psychologies.

Risk is better understood as a "mental model" [13]. This model represents reality as it manifests itself, such as "hazard", "probability" or other characteristics such as the intensity, on a preidentified scale, of an event. The risk "mental model" represents, at the same time, the way individuals and society frame such a reality (sometimes named "consequences"). How individuals talk about, and then assess, risk, taking into account contextual elements, does matter; it matters as much as the probabilistic or nonprobabilistic nature of risk and its consequences. Such a combination of matters of facts and matters of concerns [51] leads to a situation where risk assessment by experts and by laypersons arrive at different conclusions. Such dissonant situations have led to the rich and diverse literature on risk perceptions and the social construction of risk. Four central epistemic traditions may be identified.

\section{Risk Models: Four Examples of Coastal Risk Models}

There are currently several models of risk that are being actively considered within the coastal risk governance community. Most find their origin either in the environmental risk literature or in the natural hazard literature. Four dominant current models of coastal risk are identified and are assessed against permafrost thaw risk by Vanderlinden [22]: the Source Pathway Receptor Consequence model (SPRC model); the event, vulnerability, exposure model (the IPCC model); the integrated risk perception approach; the complex system centered resilience model.

The SPRC model [52] and its "inverted" deliberative version [53] are geared at representing flood and erosion risks both spatially and conceptually. They are intervention oriented, and focus on the causality connecting the source of a hazard to its consequences. Some benefits are identified when using the SPRC model in the context of permafrost thaw, such as clarification of options in terms of structural mitigation options and allowing for structured deliberations about the dynamics at work. Serious shortcomings may also be identified, such as their use may impose a simplistic external worldview on communities as they are quite technical to implement, and more importantly, they do not allow for defective institutions.

Another dominant model is the "Event, vulnerability, exposure model" [6]. This representation of risk situations is particularly interesting when exposure and vulnerability need to be distinguished in the face of extreme events. Furthermore, through vulnerability analysis, it allows for the factoring-in of defective institutions. Yet, in the case of permafrost thaw, the specification of the event, which is intertwined with exposure, may be extremely difficult to operationalize. One could legitimately wonder whether a thawing situation constitutes an event stricto sensu. Finally, system-based resilience models are increasingly successful $[54,55]$. Such an approach is recognized for its ability to take into consideration the governance of complex socio-ecosystems, yet the singularity of events within the resilience paradigm does lend itself well to situations such as permafrost thaw which are progressive with a slow onset.

An alternate route to the representation of risk situations lies in perception analysis. Considering the shortcomings of the models presented above, this may be the key to giving access to permafrost thaw situations in their complexity and diversity. Integrated perception analysis [13,56], operationalized in coastal settings by Vanderlinden et al. [57], takes into account cultural dimensions as a central feature, thus acknowledging the importance of local values and material constraints. Furthermore, through the careful analysis of all causal statements at hand, including those of scientists, perception analysis helps decipher the political economy of risk knowledge and action. 
The concept of human security may also be useful in risk modelling. More specifically, the human security concept has two strengths in that context. First, the human security concept will allow us to focus on individuals' and local communities' perceptions. Briefly said, the concept of human security aims at protecting individual(s) against physical or nonphysical, violent or nonviolent threats by including nontraditional threats to the environment, health, development or wellbeing [58-66]. Linking climate change and human security has already been advocated by several scholars [67-69]. Such a link would highlight "the importance of human security as an emerging discourse that places individuals and communities at the center of the analysis" [70] and would entail "focusing on the effect of climate change on the well-being of people and communities" [71]. Applying human security as an analytical tool in the Nunataryuk risk framework will allow integration of local cultural dimensions and risk perception/social construction by focusing primarily on individuals.

Then, as a broad concept, human security enables us to encompass every potential risk (or threats) that might be mentioned or perceived by participants. Indeed, the 1994 Human Development Report (HDR) definition includes several aspects of everyday activities [72]. This definition classifies threats to human security into seven categories: environmental security, economic security, food security, health security, community security, personal security and, finally, political security. Permafrost thaw might pose risks on several of those dimensions affecting economic and community security (infrastructures, coastal erosions, and forced migration); environmental, health and food security (ecosystem destruction or toxic gas release); personal security (distress caused by degradation of housing and future uncertainty). Applying human security dimensions to permafrost thaw offers a highly relevant analytical tool, which is broad enough to cover all potential threats and still precise enough to link those threats to grounded daily concerns.

The efforts of the Inuvialuit Regional Corporation in northwest Canada to address impacts and risks of, as well as adaptation strategies, to climate change represent a good example of an integrated, holistic approach, grounded in first-hand, local knowledge. Through a variety of methods, including workshops and interviews, "Inuvialuit contributed their views on the current and potential impacts of climate change on their communities and region" [73]. Impacts were classified into five categories: business and economy, culture and learning, health and wellbeing, subsistence hunting and fishing, and transportation and infrastructure. Identified risks associated with permafrost thaw include, for example: higher costs for construction and maintenance of infrastructure, including risks to human health and wellbeing, such as when buildings become unsafe to live in/use; stress associated with increased maintenance and adaptation; increased risks for public and private transportation as well as marine traffic due to damaged (traditional) travel routes and infrastructure; risks associated with safety of sewage system; risks for subsistence harvesting where heavily damaged areas need to be avoided. Moreover, risks in relation to "culture and learning" and especially the loss of cultural and language skills as well as values are identified as directly linked to local climate change impacts. For example, "Changing conditions are keeping some people from participating in the traditional subsistence activities" [73] and "[o]n the land living is not passed on to young harvesters-traditional value is being lost" [73].

\section{The "Compass Model" and a Methodological Flow Chart}

In the following, we propose two models, one conceptual ("Compass model"; Figure 2) and the other processual (methodological flow chart; Figure 3) to guide our work. The proposed models can be adapted to make them more appropriate for their respective social worlds, within both the different work packages of the Nunataryuk project for example, as well as in the different sites "Nunataryuk" operates in. For example, the five categories of the IRC report used in the conceptual "Compass model" can be replaced by a different categorizing system, including the human security approach. 


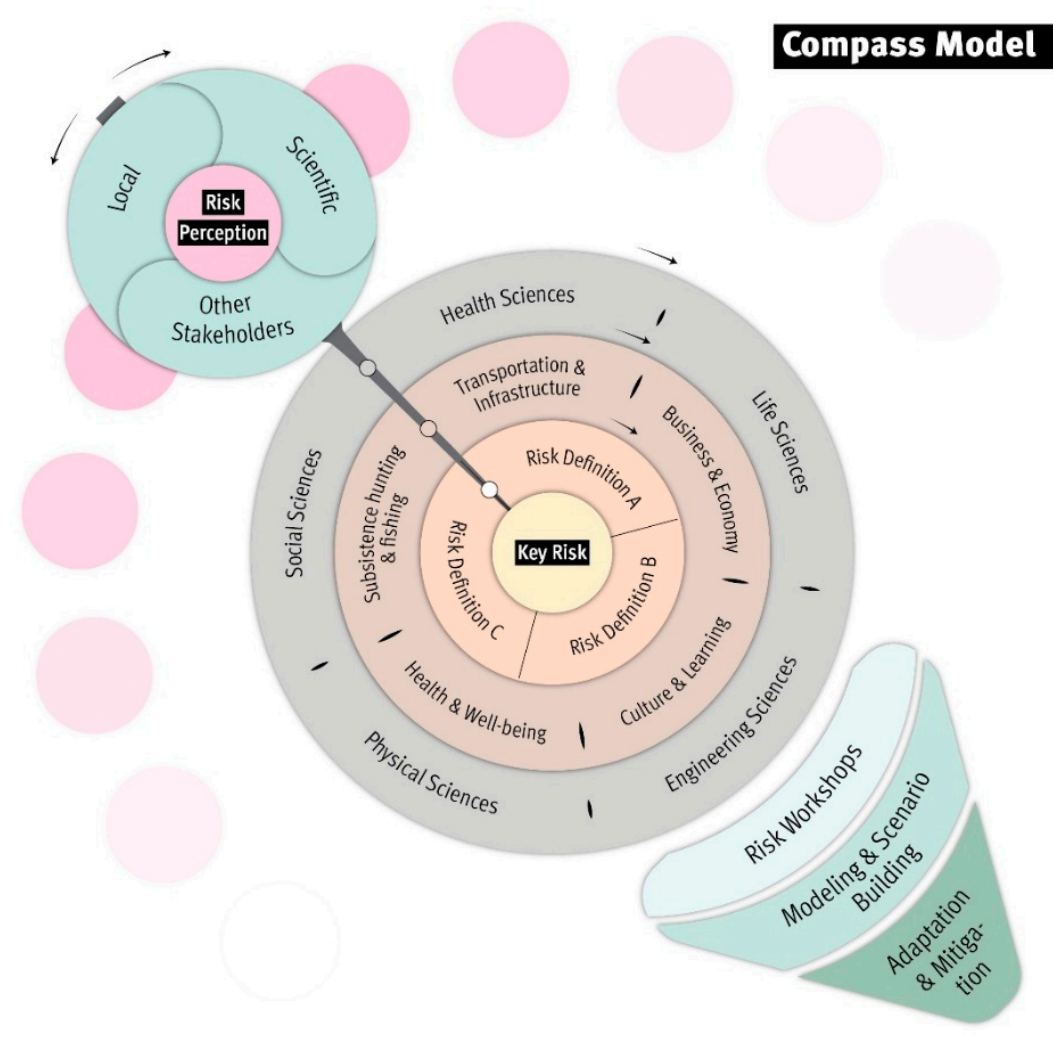

Figure 2. The "Compass model", a conceptual model to guide the identification of risks and the consequent development of adaptation and mitigation strategies in coproduction with local stakeholders. Graphical illustration by Levi Westerveld-GRID-Arendal.

\section{Methodological flow chart}

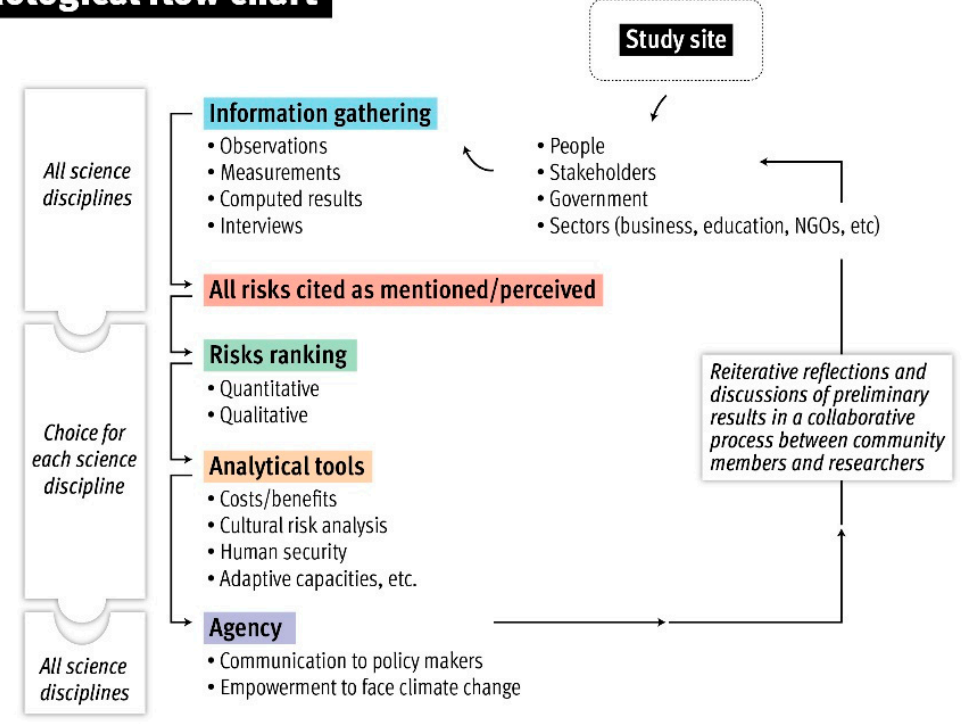

Figure 3. Methodological flow chart describing the implementation of the risk evaluation concept in the Nunataryuk project. Graphical illustration by Levi Westerveld-GRID-Arendal.

The recognition of the dual dimensions of risk as both physical (and scientifically measurable) and socially constructed has important consequences for both risk appraisal and the development of effective adaptation and mitigation strategies. A risk framework which acknowledges that "risk" is about both science and values [18] balances and integrates scientific assessments and evidence about risk factors with risk perceptions of the affected communities and creates spaces for the coproduction of knowledge and actions [12]. In 
other words, it moves beyond simply communicating risks as "matters of fact" to the affected communities to developing dialogues around "matters of concern" [19,20].

The methodological consequence of acknowledging the dual dimensions of risk is the integration of both natural and social science methods, including both local and traditional knowledge. Here, it is crucial to attend to indigenous worldviews and considering the world with its human and more-than-human actors as relational and holistic. Whereas the natural and engineering sciences provide input regarding physically measurable probabilities and consequences, the social sciences assess locally perceived risks and related concerns through methods such as participant observation and different forms of collaborative yarning, interviews, surveys or workshops and community hall meetings, etc. Hence, the social sciences deal with the knowledge, values, and worldviews of nonscientists, considered as local experts. However, also the allegedly "objective" scientific risk appraisal has been found not to be free of biases and subjectivity $[18,20]$; in this sense, also these are to some extent "perceived" risks.

An integrated approach to risk appraisal is necessarily participatory and includes the perspectives and concerns of the affected communities both in the identification and evaluation of risk as well as in the development of responses and actions $[12,13,46,49,57]$. Assuming that the affected communities can provide important local knowledge and perspectives that scientists might overlook, a participatory risk framework starts out with the identification of risk based on two kinds of input: (1) the analyses of experts, providing sound scientific knowledge about the hazard and associated probabilities and the concerns and judgements of the affected communities regarding perceived risks, and (2) the subsequent evaluation of risks and development of responses-affected stakeholders and the wider public must be consulted and able to contribute to the decision-making process in order for the measurements aimed at the reduction in risk to be effective $[12,57]$.

\subsection{The Conceptual Risk Model-The Compass Model}

Permafrost thaw is a reality across the entire Arctic coastline. Different historical, societal, and infrastructural contexts influence how permafrost thaw affects every field site and how it is perceived differently in each community. The proposed compass model is based on the recognition of the dual dimensions of risk described above and strives for participatory risk appraisal and governance, hence allowing for the inclusion of very different societal contexts [12]. It is an inductive framework based on community and scientific input.

The conceptual risk model proposes a guide to the identification of risk and consequent development of adaptation and mitigation strategies in large, multidisciplinary and applied projects such as Nunataryuk, working across several field sites. It is intended to guide the interaction between different scientific work packages and local communities. It works alongside the flow chart processual model (Figure 3), by providing a graphically appealing tool which can be used by scientists and local stakeholders alike for communicating both key risks and the processes through which key risks and associated categories are identified.

The first step is to identify risks in each of the field sites, which is achieved through invoking several sources of input including from scientists, locals, and other stakeholders (see Figure 2). Experts from the different natural and engineering sciences involved provide scientific assessments of risks in the various domains of terrestrial, coastal and subsea permafrost, coastal waters, infrastructure, health and pollution, and natural resources and economy. Second, through literature reviews, consultation meetings, qualitative interviews, focus group discussions, and informal conversations, locally perceived risks in every community are assessed, aimed at the identification of which physical impacts are observed in the communities and whether this is associated with concerns.

In a second step, a series of participatory risk workshops in each of the field sites provide open spaces for the communication and discussion of both the scientifically assessed and locally perceived risks. Scientific experts and local knowledge holders exchange 
information and concerns, evaluate each of the risks, and reach a consensus regarding key risks in every community.

These identified key risks should in a third step feed back into the scientific work packages, guiding the subsequent work in the different field sites. This in turn ensures that local concerns are taken into account and guide the study design of the project, making sure that the outcomes of the risk assessment are relevant to local partners and residents where primary data gathering takes place. In a fourth step in this hermeneutical process, a final workshop or similar event in all participating communities will inform the public about the outcomes of the studies. Ideally, this is accompanied by a physical product such as a brochure, booklet, website or film, explaining in lay language the outcomes of the research conducted within Nunataryuk and/or the compass model in physical form. During the final workshops in local communities, direction for further research will be gathered, thus ensuring research priorities in the north are continually being decided upon by Northerners.

Instead of only identifying key risks, which local communities are more often than not already acutely aware of, the outcomes of the diverse studies should feed directly into the development of adaptation and mitigation strategies. This, as well as innovative visual and oral methods, should in turn counteract so-called research fatigue, which is encountered in several communities dealing with permafrost thaw [74-76]. Indigenous peoples who have been living in close interaction with their wider surroundings for centuries observe the changes happening and look for solutions to the issues and challenges they face in their daily lives. Northerners have been adapting to changes caused by permafrost thaw for a long time, and they are equally aware of how little mitigative action can be taken in the Arctic and sub-Arctic itself. Since the problem of thawing ground is caused mainly by consumption and production patterns of people living in the south, the concept of "equitable mitigation" is becoming increasingly more important [77]. There are limits to how much relatively small circumpolar communities can do to minimize their carbon and other climate-affecting emissions. They can and do, however, ask scientists, such as those involved in Nunataryuk, to educate audiences in the countries that contribute the most of the global warming about the unequal effects, such as the fact that Arctic communities are already having to pay the price for the lifestyles associated with the consumer societies of today.

An advantage of the compass model is that it connects more easily (relative to other models) with everyday life of laypeople. A compass, a widely known symbolic representation of orientation and travel, as well as the overall round, organic shapes, are reminiscent of objects used in everyday life and thus are more easily and intuitively understood. Shortcomings of the compass model include one at the epistemological level: the compass may symbolically be associated with European or other foreign explorers of the Arctic, whereas finding your way and transmitting this knowledge is traditionally mainly an oral affair, as well as based on watching and learning by doing in indigenous communities [75]. This knowledge is based on intricate knowledge of the land. However, over recent decades young people increasingly rely on technology to find their way. This is partly due to the fact that indigenous epistemes have been violently pushed aside by processes of colonialization. Further, traditional knowledge and skills of navigating on the land have become more unreliable, due to, for example, changing weather and sea ice conditions $[73,76]$. This problem could be addressed by finding different symbols that are more culturally appropriate to the respective areas they will be put to use in.

The second shortcoming concerns the lack of emphasis on the hermeneutical process between data gathering and consequent input from experts at all levels including scientists as well as the input of local knowledge holders. This shortcoming might be addressed by a more creative visualization. This interaction between the mentioned stakeholders should ensure the incentive and direction for further action is taken on all sides. An intrinsic risk associated with finding solutions to highly complex situations is that people may turn their heads the other way in order to protect themselves from the consequences of the perceived 
dire situation. Knowledge itself may not be sufficient to engender behavioral changes, whereas concern for certain issues, such as polar ice loss or associated local and global risks of permafrost thaw, might be able to cause said changes [78]. Instead, the emphasis in this participatory process must be on finding short- and long-term solutions together, as well as turning the risks associated with permafrost thaw into a "matter of concern" for southern audiences as well.

\subsection{Processual Risk Model-A Methodological Flow Chart}

Here, we propose a methodological flow chart (Figure 3) - a processual model—which shows how to implement what is in the conceptual model outlined above. The methodological flow chart we introduce can be used to produce a conceptual framework that fits the specific case of Nunataryuk. Our conceptual framework motivates coproduction of risk management with locals in identification of risks from permafrost thaw. The processual risk model supports the users to carry out systematic data gathering. It is designed to align data input from several different field sites and research disciplines. In the specific case of our research on the Arctic coasts in Nunataryuk the field sites are in four countries (Canada, Denmark (Greenland), Norway (Svalbard), and Russia). At each field site, input of data could consist of observations, computed results, interviews, and workshops. The collection of data can be from different disciplines, but it does not have to be. It can be a social science research team that provides input data from interviews and observations. For all qualitative data, it is important to include a broad sample of interviewees, from local stakeholders to government representatives and different economic actors. This ensures that a diversity of views will be heard. Different people provide their perspectives of how they perceive risks in their lives and communities.

Input from the computed results are based on measurements collected at the study site. This input could be direct observations such as measured ground temperatures, weather data (e.g., precipitation) or assessment of infrastructure damages. However, it could also be derived products or forecasts based on modelling approaches.

In our multidisciplinary research team, various types of inputs will be considered, some examples may include measurements of coastal erosion, subsea and frozen ground temperatures, impacts on infrastructure, examination of anthrax and epidemiologic modeling as well as studies on subjective wellbeing in areas with permafrost thaw, climate projections, data on community development as well as local adaptation and mitigation strategies. All data gathered by the different research disciplines can be utilized in the model. When all data have been gathered, they can be listed in a raw format as measured or as mentioned by scientists and community members. After the data have been collected, risk is identified based on a review assessment. The interview data reflect the community's perception of risk. This approach allows for adding risks into the model directly as they are perceived by local stakeholders and community members.

Data inserted into the model may be observed changes, computational models, stakeholder concerns, etc. After gathering all risks, the scientists together with community representatives carry out a risk ranking. The different risks collected as part of the data collection are ranked based on a variety of factors, such as word counts, or perceived level of exposure and threat/risk.

With a full list of all risks collected at the study site, the next step will be to apply different analytical tools such as a cost/benefit analysis, cultural risk analysis or human security assessment. The aim of the analysis is to reduce the risks related to permafrost thaw (in the case of Nunataryuk) and to produce an evidence-based foundation for agency that can reverse the risk. The most important final step is to have interactive communication about the results between the scientists and impacted communities experiencing risk. If more structural change is needed-e.g., a new structure of governance, or new allocation of funds for infrastructure damages-it is also important to communicate the results to decision-making levels in local, regional, and national government bodies. Allocation of new funds is very seldom an option. It is typically about prioritizing the funds already 
available. Therefore, the risk evaluation can help communities decide how to spend the limited funds available in a way that optimizes their perception of quality of life. We suggest that the end-goal of the processual flow chart model is to gather risk systematically, make assessments and apply different tools and analyses that can empower Arctic coastal communities in facing permafrost thaw risks.

The models proposed here can also be seen as part of the "boundary objects" within a multidisciplinary project, meaning the set of material and processual cooperation arrangements that enable outcomes even though consensus is not always achieved. Star [79] names three components of boundary objects. First is interpretive flexibility, meaning that the object can mean different things to different people, depending, for example, on what kind of information they are looking for. Second is the material or organizational structure of different types of boundary objects and third is scale and granularity [77]. The materiality of a model as an object, he explains, "derives from action, not from a sense of prefabricated stuff or 'thing'-ness" [79]. He goes on to explicate how "[b]oundary objects are a sort of arrangement that allow different groups to work together" and enable cooperation even when consensus is not achieved [79]. When Star and Griesemer [80] put forward the concept of "boundary objects", they defined the idea and explained why consensus is not always necessary: the object (remember, to read this as a set of work arrangements that are at once material and processual) resides between social worlds (or communities of practice) where it is ill structured. When necessary, the object is worked on by local groups who maintain its vaguer identity as a common object, while making it more specific, more tailored to local use within a social world, and therefore useful for work that is not interdisciplinary. Groups that are cooperating without consensus tack back-and-forth between both forms of the object [79].

As mentioned before, this means the proposed models can be adapted to make them more appropriate for their respective social worlds, within both the different work packages of the project for example, as well as in the different sites "Nunataryuk" operates in. For example, the five categories of the IRC report used in the compass model could be replaced by a different categorizing system, including the human security approach. Furthermore, Star [79] explains, that "when the movement between the two (or more, Annot. by the authors) forms either scales up or becomes standardized, then boundary objects begin to move and change into infrastructure, into standards (particularly methodological standards), and into things and yet other processes". Thus, the models described in this paper can be seen as low-scale, modifiable vehicles for further action and cooperation among the different groups that are being engaged. This can eventually lead to the above-mentioned standardization or development of methodological standards.

\section{Discussion and Conclusions}

We have presented a conceptual risk framework and a processual risk model that incorporate the notion of the dual dimensions of risk, which we then relate to the case of thawing permafrost in Arctic coastal communities. Our aim with the development of a risk framework is to arrive at a model that can facilitate the gathering of coastal risks systematically, make assessments and apply different tools and analysis that can aid empowerment to effectively manage and respond to permafrost thaw risks in Arctic coastal communities and to sketch out a step-by-step process for multidisciplinary risk identification, also to be used in other, similar projects.

An international risk workshop with broad participation from across science and other disciplines within the Nunataryuk project provided the starting point for our internal risk framework discussions, theoretical considerations, and the risk model conceptualization. Results from local community meetings and interviews with stakeholders from fieldwork conducted across case studies, including data gathered on the socio-economic and cultural contexts in our coastal field sites, also contributed important context for discussions on the framework development. Our results consist of a conceptual model of the general process, 
presented as a compass-type model, and a processual risk model, which is illustrated as a flow chart.

Our proposed framework - the combination of the conceptual and processual modelcan be used for guiding large multidisciplinary projects, such as Nunataryuk, in identifying major risks to climate change in coproduction of knowledge with stakeholders. This, in turn, will provide critical context and data for subsequent processes in our next steps to develop strategies for adaptation and mitigation in coproduction with stakeholders to address those risks.

A central element in our conceptual framework is the focus on the dual dimensions of risk and the importance of risk perceptions of the affected communities, which facilitate the coproduction of knowledge. The recognition of the dual dimensions of risk as both physical and socially constructed is important in the identification of major risks.

With the "Compass model" and the "methodological flow chart" we have proposed a guide to the identification of risk and consequent development of adaptation and mitigation strategies in large multidisciplinary projects. It is intended to guide the interaction between different scientific work packages and local communities. It helps facilitate collaboration and the coproduction of knowledge in these large, applied projects. Applying the steps identified in our methodological flow chart ensures that this codesigned analysis derives from a rigorous, thorough methodology that is comparable from one field site to another and from one discipline to another.

The importance of a multidisciplinary approach to risk assessment is reflected in our conceptual model description. Our conceptual model (compass model and methodological flow chart) ensures a multidisciplinary approach based on codesign, informed by stakeholder risk perception, and allowing for different quantitative or qualitative risk definitions.

There is a need for an approach that allows selection of the most appropriate risk definition for the particular case, in collaboration with stakeholders. In other words, our model framework recognizes that not one risk definition will fit all cases studied. Our model provides room for different risk definitions. We introduce an "open slot" in the model to plug in appropriate risk definitions based on the specific case and application.

While some shortcomings of the "Compass model" remain, including the lack of emphasis on the process between data gathering and input from experts, local knowledge holders, and scientists, there are also important strengths. The framework helps facilitate the connection with local stakeholders, provides for community input and a systematic data gathering. It guides the interaction between the local communities and stakeholders with their perceived risks and researchers from different study regions and field sites and varying local environmental and social contexts.

Looking ahead, the next steps will include efforts to apply the framework in a set of community risk workshops to identify key socio-economic and cultural risks from thawing permafrost and to analyze the potential for reducing the level of risks by coproduction of knowledge with stakeholders. This will lead to the development of a risk management framework adapted to the Arctic coastal context. Such a framework aids the identification and evaluation of adaptation and mitigation strategies and reduces identified key risks. At the same time, such a framework is not limited to Arctic coastal situations. We are convinced that its applicability is much wider and that it can be easily adapted to other geographic areas and social contexts in which local risk assessments are needed or desired.

Author Contributions: Conceptualization, J.N.L. and P.S.; writing-original draft preparation, all authors; writing - review and editing, all authors. All authors have read and agreed to the published version of the manuscript.

Funding: This research was supported by the Nunataryuk project, funded by the European Union's Horizon 2020 Research and Innovation Programme under grant agreement No. 773421.

Institutional Review Board Statement: Not applicable.

Informed Consent Statement: Informed consent was obtained from all subjects involved in the study. 
Data Availability Statement: Data sharing not applicable.

Acknowledgments: Thank you to Jonathan William Wood for assistance with proof reading, and to Levi Westerveld at GRID-Arendal for graphical illustrations-Figures 2 and 3. Figure 1 was produced as part of the Nunataryuk project, which has received funding under the European Union's Horizon 2020 Research and Innovation Programme under grant agreement No. 773421.

Conflicts of Interest: The authors declare no conflict of interest.

\section{References}

1. Whiteman, C.A. Cold Region Hazards and Risks; Wiley-Blackwell: Hoboken, NJ, USA, 2011; p. 366.

2. Haeberli, W.; Whiteman, C. Snow and Ice-Related Hazards, Risks and Disasters: A General Framework. In Snow and Ice-Related Hazards, Risks and Disasters; Haeberli, W., Whiteman, C., Shroder, J.F., Eds.; Elsevier: Waltham, MA, USA, 2015 ; Volume 1, pp. 1-34.

3. United Nations. 2009 UNISDR Terminology on Disaster Risk Reduction; UNSDR: Geneva, Switzerland, 2009.

4. Nicholls, R.; Zanuttigh, B.; Vanderlinden, J.P.; Weisse, R.; Silva, R.; Hanson, S.; Narayan, S.; Hoggart, S.; Thompson, R.C.; de Vries, W.; et al. Developing a holistic approach to assessing and managing coastal flood risk. In Coastal Risk Management in a Changing Climate; Butterworth-Heinemann: Oxford, UK, 2015; pp. 9-53.

5. Spratt, D.; Dunlop, I. Existential Climate-Related Security Risk: A Scenario Approach; BT Policy Paper: Melbourne, Australia, 2019.

6. Intergovernmental Panel on Climate Change (IPCC). Managing the Risks of Extreme Events and Disasters to Advance Climate Change Adaptation (SREX); IPCC: Geneva, Switzerland, 2012.

7. UNDRO. Natural Disasters and Vulnerability Analysis. In Proceedings of the Report of Expert Group Meeting, Geneva, Switzerland, 9-12 July 1979.

8. Liu, Y.; Chen, J. Future global socioeconomic risk to droughts based on estimates of hazard, exposure, and vulnerability in a changing climate. Sci. Total Environ. 2021, 751, 142159. [CrossRef]

9. Zhou, Q.; Leng, G.; Feng, L. Predictability of state-level flood damage in the conterminous United States: The role of hazard, exposure and vulnerability. Sci. Rep. 2017, 71, 1-11. [CrossRef] [PubMed]

10. Flynn, M.; Ford, J.D.; Labbé, J.; Schrott, L.; Tagalik, S. Evaluating the effectiveness of hazard mapping as climate change adaptation for community planning in degrading permafrost terrain. Sustain. Sci. 2019, 14, 1041-1056. [CrossRef]

11. Aven, T.; Renn, O. Risk Management and Governance; Springer: Berlin, Germany, 2010.

12. Renn, O. White Paper on Risk Governance: Towards an Integrative Approach; The International Risk Governance Council: Geneva, Switzerland, 2005.

13. Renn, O. Risk Governance: Coping with Uncertainty in a Complex World; Earthscan: London, UK, 2008.

14. Field, C.B.; Barros, V.; Stocker, T.F.; Dahe, Q.; Dokken, D.J.; Ebi, K.L.; Midgley, P.M. Managing the Risks of Extreme Events and Disasters to Advance Climate Change Adaptation; Special Report of the Intergovernmental Panel on Climate Change; Cambridge University Press: Cambridge, UK, 2012.

15. Aven, T.; Renn, O. On risk defined as an event where the outcome is uncertain. J. Risk Res. 2009, 12, 1-11. [CrossRef]

16. Stirling, A. Risk at a turning point? J. Risk Res. 1998, 1, 97-109. [CrossRef]

17. Stirling, A. Risk, uncertainty and precaution: Some instrumental implications from the social sciences. In Negotiating Change; Berkhout, F., Leach, M., Scoones, I., Eds.; Elgar: London, UK, 2003; pp. 33-76.

18. Pidgeon, N. Risk assessment, risk values and the social science programme: Why we do need risk perception research. Reliab. Eng. Syst. Saf. 1998, 59, 5-15. [CrossRef]

19. Stewart, I.S.; Lewis, D. Communicating contested geoscience to the public: Moving from 'matters of fact' to 'matters of concern'. Earth Sci. Rev. 2017, 174, 122-133. [CrossRef]

20. Chouinard, O.; Baztan, J.; Vanderlinden, J.P. (Eds.) Les Zones Côtières Face au Changement Climatique: Le Défi de la Gestion Intégrée; Presses de l'Université du Québec: Quebec City, QC, Canada, 2011.

21. Zanuttigh, B.; Nichols, R.; Vanderlinden, J.P.; Burcharth, H.F.; Thomson, R.C. (Eds.) Coastal Risk Management in a Changing Climate; Elsevier/Butterworth-Heinemann: London, UK, 2015.

22. Vanderlinden, J.P.; Overduin, P.; Forbes, D.L.; Shadrin, V.; Doloisio, N. Scoping the Risks Associated with Accelerated Coastal Permafrost Thaw: Lessons from Bykovsky (Sakha Republic) and Tuktoyaktuk (Northwest Territories). In Proceedings of the EGU General Assembly Conference Abstracts, Vienna, Austria, 8-13 April 2018; Volume 20.

23. Ingeman-Nielsen, T. And Lemay, M. Built infrastructure. In Adaptation Actions for a Changing Arctic: Perspectives from the Baffin Bay/Davis Strait Region; Arctic Monitoring and Assessment Programme (AMAP): Oslo, Norway, 2018; pp. 261-299.

24. JCSS (Joint Committee on Structural Safety). Risk Assessment in Engineering_Principles, System Representation E Risk Criteria; Faber, M.H., Ed.; JCSS: Shanghai, China, 2008.

25. Public Safety Canada. All Hazards Risk Assessment-Methodology Guidelines; Public Safety Canada: Ottawa, Canada, 2011.

26. Brooks, H.; Doré, G.; Locat, A.; Lemieux, C. Quantitative Risk Analysis of Linear Infrastructure: State of the Practice and Research Plan. In Proceedings of the International Conference on Cold Regions Engineering, Salt Lake City, UT, USA, 19-22 July 2015; pp. 629-640. [CrossRef]

27. Engineer Canada. PIEVC Engineering Protocol for Climate Change Infrastructure Vulnerability Assessment-Part I, Version 10; Public Infrastructure Engineering Vulnerability Committee: Ottawa, Canada, 2011. 
28. BGC Engineering, Inc. Climate Change Vulnerability Assessment for NWT Highway 3. Final; Government of the Northwest Territories, Department of Transportation: Yellowknife, NT, Canada, 2011.

29. Allard, M.; Lemay, M.; Barrette, C.; L’Hérault, E.; Sarrazin, D. Chapter 6. Permafrost and climate change in Nunavik and Nunatsiavut: Importance for municipal and transportation infrastructures. In Nunavik and Nunatsiavut: From Science to Policy: An Integrated Regional Impact Study (IRIS) of Climate Change and Modernization; ArcticNet Inc.: Quebec City, QC, Canada, 2009; pp. 171-194.

30. L'Hérault, E.; Allard, M.; Fortier, D.; Carbonneau, A.-S.; Doyon-Robitaille, J.; Lachance, M.-P.; Ducharme, M.-A.; Larrivée, K.; et Chantal Lemieux, K.G. Production de cartes des Caractéristiques du Pergélisol afin de Guider le Développement de L'environnement bâti pour Quatre Communautés du Nunavik. Rapport Final; Centre d'Etudes Nordiques (CEN), 2013; pp. 1-84. Available online: https://www.ouranos.ca/publication-scientifique/RapportAllard2013_FR.pdf (accessed on 1 March 2021).

31. Abass, K.; Huusko, A.; Knutsen, H.K.; Nieminen, P.; Myllynen, P.; Meltzer, H.M.; Vahakangas, A.; Rautio, A. Quantitative estimation of mercury intake by toxicokinetic modelling based on total mercury levels in humans. Environ. Int. 2018, 114, 1-11. [CrossRef]

32. Carlsson, P.; Breivik, K.; Brorström-Lundén, E.; Cousins, I.; Christensen, J.; Grimalt, J.O.; Halsall, C.; Kallenborn, R.; Abass, K.; Lammel, G.; et al. Polychlorinated biphenyls (PCBs) as sentinels for the elucidation of Arctic environmental change processes: A comprehensive review combined with ArcRisk project results. Environ. Sci. Pollut. Res. Int. 2018, 25, 22499-22528. [CrossRef] [PubMed]

33. Schuster, P.F.; Schaefer, K.M.; Aiken, G.R.; Antweiler, R.C.; Dewild, J.F.; Gryziec, J.D.; Gusmeroli, A.; Hugelius, G.; Jafarov, E.; Krabbenhoft, D.P.; et al. Permafrost stores a globally significant amount of mercury. Geophys. Res. Lett. 2018, 45, 1463-1471. [CrossRef]

34. Waits, A.; Emelyanova, A.; Oksanen, A.; Abass, K.; Rautio, A. Human Infectious Diseases and the Changing Climate in the Arctic. Environ. Int. 2018, 121, 703-713. [CrossRef]

35. Omazic, A.; Bylund, H.; Boqvist, S.; Högberg, A.; Björkman, C.; Tryland, M.; Evengård, B.; Koch, A.; Gerggren, C.; Malogolovkin, A.; et al. Identifying climate-sensitive infectious diseases in animals and humans in Northern regions. Acta Vet. Scand. 2019, 61, 53. [CrossRef] [PubMed]

36. Fjeld, R.; Esienberg, N.; Compton, K. (Eds.) Quantitative Environmental Risk Analysis for Human Health; Wiley Interscience: Hoboken, NJ, USA, 2007.

37. United States Environmental Protection Agency; US Environmental Protection Agency Office of the Science Advisor Risk Assessment Forum Framework for Human Health Risk Assessment to Inform Decision Making. 2014. Available online: https: //www.epa.gov/sites/production/files/2014-12/documents/hhra-framework-final-2014.pdf (accessed on 19 December 2020).

38. Abass, K.; Huusko, A.; Nieminen, P.; Myllynen, P.; Pelkonen, O.; Vahakangas, K.; Rautio, A. Estimation of health risk by using toxicokinetic modelling: A case study of polychlorinated biphenyl PCB153. J. Hazard. Mater. 2013, 261, 1-10. [CrossRef]

39. Abass, K.; Emelyanova, A.; Rautio, A. Temporal trends of contaminants in Arctic human populations. Environ. Sci. Pollut. Res. 2018, 25, 28834. [CrossRef] [PubMed]

40. Wania, F.; Binnington, M.; Curren, M. Mechanistic modeling of persistent organic pollutant exposure among indigenous Arctic populations: Motivations, challenges, and benefits. Environ. Rev. 2017, 25, 396. [CrossRef]

41. Hoek, G.; Ranzi, A.; Alimehmeti, I.; Ardeleanu, E.R.; Arrebola, J.P.; Ávila, P.; Candeias, C.; Colles, A.; Crișan, G.C.; Dack, S.; et al. A review of exposure assessment methods for epidemiological studies of health effects related to industrially contaminated sites. Epidemiol Prev. 2018, 42, 21-36. [CrossRef]

42. Vasvári, T. Risk, Risk Perception, Risk Management-A Review of the Literature. Public Financ. Q. 2015, 1, $29-48$.

43. Slovic, P. The Psychology of Risk; Saúde Society: São Paulo, Brazil, 2010; Volume 19, pp. 731-747.

44. Douglas, M.; Wildavsky, A.B. Risk and Culture: An Essay on the Selection of Technological and Environmental Dangers; University of California Press: Berkeley, CA, USA, 1982.

45. McNeeley, S.M.; Lazrus, H. The Cultural Theory of Risk for Climate Change Adaptation. WeatherClim. Soc. 2014, 6, 506-519. [CrossRef]

46. Slovic, P. Perception of risk: Reflections on the psychometric paradigm. In Social Theories of Risk; Krimsky, S., Golding, D., Eds.; Praeger: Westport, CT, USA, 1992; pp. 117-152.

47. Lechowska, E. What determines flood risk perception? A review of factors of flood risk perception and relations between its basic elements. Nat. Hazards 2018, 94, 1341-1366. [CrossRef]

48. Sjöberg, L. Factors in Risk Perception. Risk Anal. 2000, 20, 1-11. [CrossRef]

49. Wachinger, G.; Renn, O.; Begg, C.; Kuhlicke, C. The Risk Perception Paradox-Implications for Governance and Communication of Natural Hazards. Risk Anal. 2013, 33, 1049-1065. [CrossRef] [PubMed]

50. Kahan, D.; Peters, E.; Wittlin, M.; Slovic, P.; Ouellette, L.; Braman, D.; Mandel, G. The polarizing impact of science literacy and numeracy on perceived climate change risks. Nat. Clim. Chang. 2012, 2, 732-735. [CrossRef]

51. Latour, B. What Is Style of Matters of Concern? Van Gorcum: Amsterdam, The Netherlands, 2005.

52. Narayan, S.; Nicholls, R.J.; Clarke, D.; Hanson, S.; Reeve, D.; Horrillo-Caraballo, J.; Vanderlinden, J.P. The SPR systems model as a conceptual foundation for rapid integrated risk appraisals: Lessons from Europe. Coast. Eng. 2014, 87, 15-31. [CrossRef]

53. Kane, I.O.; Vanderlinden, J.P.; Baztan, J.; Touili, N.; Claus, S. Communicating risk through a DSS: A coastal risk centred empirical analysis. Coast. Eng. 2014, 87, 240-248. [CrossRef] 
54. Vanderlinden, J.P.; Baztan, J.; Coates, T.; Davila, O.G.; Hissel, F.; Kane, I.O.; Touil, N. Nonstructural approaches to coastal risk mitigations. In Coastal Risk Management in a Changing Climate; Zanuttigh, B., Nichols, R., Vanderlinden, J.P., Burcharth, H.F., Thomson, R.C., Eds.; Elsevier/Butterworth-Heinemann: London, UK, 2015; pp. 237-274.

55. Wardekker, J.A.; de Jong, A.; Knoop, J.M.; van der Sluijs, J.P. Operationalising a resilience approach to adapting an urban delta to uncertain climate changes. Technol. Forecast. Soc. Chang. 2010, 77, 987-998. [CrossRef]

56. Renn, O.; Rohrmann, B. Cross-cultural risk perception: State and challenges. In Cross-Cultural Risk Perception; Springer: Boston, MA, USA, 2000; pp. 211-233.

57. Vanderlinden, J.P.; Baztan, J.; Touili, N.; Kane, I.; Rulleau, B.; Simal, P.; Zagonari, F. Coastal Flooding, Uncertainty and Climate Change: Science as a Solution to (mis) Perceptions? A Qualitative Enquiry in Three Coastal European Settings. J. Coast. Res. 2017, 77, 127-133. [CrossRef]

58. Boutros-Ghali, B. An Agenda for Peace: Preventive Diplomacy, Peace-Making and Peace-Keeping; Report of the Secretary-General Pursuant to the Statement Adopted by the Summit Meeting of the Security council on 31 January 1992 (A/47/277); United Nations Organisation: New York, NY, USA, 1992.

59. Buzan, B.; Waever, O.; de Wilde, J. Security, a New Framework for Analysis; Lynne Rienner Publishers: Boulder, CO, USA, 1998.

60. King, G.; Murray, C.J.L. Rethinking Human Security. Political Sci. Q. 2001, 116, 585-610. [CrossRef]

61. Rioux, J.F. (Ed.) La Sécurité Humaine, une Nouvelle Conception des Relations Internationals; Coll. Raoul-Dandurand, Paris L'Harmattan: Paris, France, 2001.

62. David, C.P.; Roche, J.J. Théories de la sécurité; Coll. Clefs politiques Paris Montchrestien: Paris, France, 2002.

63. Kaldor, M. La Sécurité Humaine: Un Concept Pertinent? Politique étrangère Institut français des relations internationales (Hiver): Paris, France, 2006; pp. 901-914.

64. Owen, T. The critique that dog doesn't bite: A response to David Chandler's "human security: The dog that didn't bark". Secur. Dialogue 2008, 4, 445-454. [CrossRef]

65. Alkire, S. Human Development: Definitions, Critiques and Related Concepts; Human Development Research Paper 2010/01; United Nations Development Programme: New York, NY, USA, 2010.

66. Fukuda-Parr, S.; Messineo, C. Human Security: A critical review of the literature; Working Paper 11; Centre for Research on Peace and Development (CRPD): Leuven, Belgium, 2012.

67. Gasper, D. The idea of Human Security. In Climate Change, Ethics, and Human Security; O'Brien, K., Saint-Clair, A.L., Kristoffersen, B., Eds.; Cambridge University Press: Cambridge, UK, 2010; pp. $23-46$.

68. Adger, W.N.; Pulhin, J.M.; Barnett, J.; Dabelko, G.D.; Hovelsrud, G.K.; Levy, M.; Spring, Ú.; Vogel, C.H. Human Security, in International Panel on climate Change (IPCC), Climate Change 2014: Impacts, Adaptation, and Vulnerability. Part A: Global and Sectoral Aspects. In Contribution of Working Group II to the Fifth Assessment Report of the Intergovernmental Panel on Climate Change; Cambridge University Press: Cambridge, UK, 2014; pp. 755-791.

69. Larsen, J.N.; Anisimov, O.A.; Constable, A.; Hollowed, A.B.; Maynard, N.; Prestrud, P.; Prowse, T.D.; Stone, J.M.R. Polar Regions, in International Panel on climate Change (IPCC), Climate Change 2014: Impacts, Adaptation, and Vulnerability. Part A: Global and Sectoral Aspects. In Contribution of Working Group II to the Fifth Assessment Report of the Intergovernmental Panel on Climate Change, Cambridge; Cambridge University Press: Cambridge, UK, 2014; pp. 1567-1612.

70. O'Brien, K.; Saint-Clair, A.L.; Kristoffersen, B. Climate Change, Ethics, and Human Security; Cambridge University Press: Cambridge, $\mathrm{UK}, 2010$.

71. Barnett, J. Climate Change Science and Policy, as if People Mattered. In Climate Change, Ethics, and Human Security; O'Brien, K., Saint-Clair, A.L., Kristoffersen, B., Eds.; Cambridge University Press: Cambridge, UK, 2010; pp. 47-62.

72. United Nations. Human Development Report; United Nations Development Programme; Oxford University Press: New York, NY, USA, 1994.

73. Inuvialuit Regional Corporation. Inuvialuit on the Frontline of Climate Change: Development of a Regional Climate Change Adaptation Strategy. 2016. Available online: https://irc.inuvialuit.com/system/files/Inuvialuit $\% 20$ on $\% 20$ the $\% 20$ Frontline $\% 20$ of\%20Climate\%20Change-Final-Feb2018\%20\%28SMALL\%29.pdf (accessed on 16 November 2020).

74. Carr, K.; Natcher, D.C.; Olfert, R. Measuring the economic impact of publicly funded research in Northern Canada. Polar Geogr. 2013, 36, 291-304. [CrossRef]

75. Bennett, T.D.; Lantz, T.C. Participatory photomapping: A method for documenting, contextualizing, and sharing indigenous observations of environmental conditions. Polar Geogr. 2014, 37, 28-47. [CrossRef]

76. Pearce, T.; Ford, J.D.; Caron, A.; Kudlak, B.P. Climate change adaptation planning in remote, resource-dependent communities: An Arctic example. Reg. Environ. Chang. 2012, 12, 825-837. [CrossRef]

77. Robiou du Pont, Y.; Jeffery, M.L.; Gutschow, J.; Rogelj, J.; Christoff, P.; Meinshausen, M. Equitable mitigation to achieve the Paris Agreement goals. Nat. Clim. Chang. 2017, 7, 1-8. [CrossRef]

78. Smith, E.; Eder, C.K.; Katsanidou, A. On Thinning Ice: Understanding the Knowledge, Concerns and Actions Towards Melting Polar Ice in Germany. In Proceedings of the ECPR General Conference 2018, Hamburg, Germany, 24 August 2018.

79. Star, S.L. This is Not a Boundary Object: Reflections on the Origin of a Concept. Sci. Technol. Hum. Values 2010, 35, 601-617. [CrossRef]

80. Star, S.L.; Griesemer, J. Institutional ecology, 'Translations', and Boundary objects: Amateurs and professionals on Berkeley's museum of vertebrate zoology. Soc. Stud. Sci. 1989, 19, 387-420. [CrossRef] 